\title{
Sustainability, Trust and Blockchain Applications: Best Practices and Fintech Prospects
}

\begin{abstract}
Since the adoption of the SDGs in 2015, it has been a 5-year journey of trial and error experimentations all over the world to come up with innovative solutions beyond business-as-usual and get the job done. In this paper, we assess blockchain-backed solutions beyond the hype. While the technology has a promising potential to trigger disruptive innovations to fulfill the SGDs, it is not mature yet with many gaps in terms of approaches and tools to develop blockchain use cases, monitor and evaluate blockchain experiments, mitigate associated risks and ethical considerations while managing changes within organizations leading blockchain-powered platforms. It is only by filing these gaps that blockchain can deliver its promises and may be effectively used as an SDG accelerator. Islamic finance can play a key role in shaping the transition towards a more circular economy. One promising way of doing so, is by scaling-up the use of blockchainenabled solutions in the practices of circular economy and Islamic finance. As the technology is still getting mature, more innovative and applied research is needed to capitalize on the lessons learned within various geographies and across a wide range of economic, social, and environmental spectrums.
\end{abstract}

Key Words: Blockchain, SDGs, innovation, Islamic finance, circular economy

JEL Codes:

\author{
Ahmet Faruk Aysan \\ Hamad Bin Khalifa University, \\ College of Islamic Studies, Islamic Finance and Economy Program, \\ Qatar Foundation \\ aaysan@hbku.edu.qa
}

Fouad Bergigui

SDI Global Consult

f.bergigui@sdi.world 


\section{Sustainability, Trust and Blockchain Applications: Best Practices and Fintech Prospects}

\section{Introduction}

Undeniably, blockchain, and distributed ledger technologies are disrupting traditional business models in so many ways, including within the international development space. Driven by the hype to embrace, blockchain-powered pilots, and experiments to design minimum viable products and test proofs of concepts are burgeoning across spectrums all over the world. Against this backdrop, to produce sustainable development impact and accelerate the ongoing efforts to meet the SDGs by 2030, many are willing to prototype promising use cases in an attempt to harness the potential of blockchain-enabled solutions.

Now, while virtually there is so much one can do with blockchain-backed applications, there is also a huge lack of evidence to truly assess the contribution of the blockchain technology to sustainable development. Even more, thought-provoking is the chronic lack of data along the blockchain industry. Ironically, in contrast with its promising potential to foster trust and accountability, the overall blockchain industry appears relatively opaque because of the overall scarcity of data from pilots and experiments which remain largely under-studied especially with regards to blockchain-based applications for social impact and sustainable development.

In the absence of aggregate data to build the body of knowledge about blockchain use cases for the SDGs, organizations, and individuals implementing blockchain projects for sustainable development may not be able to learn from the existing practices and consequently improve their own projects. Such knowledge is critical to extract good practices and lessons learned, to share experiences and to catalyze joint efforts towards reaching economies of scale. Besides, such knowledge paves the way to functional blockchain ecosystems that can produce nationwide solutions instead of experimentation silos with little or no proven impact at scale.

Admittedly, this could be explained by the fact that we are still in the early days of the blockchain technology as it is getting mature and the wave of its adoption is building and breaking across the shorelines of the international development practice. While we can 
learn from the trials and errors on experimentations conducted by the early movers at the early days of a nascent technology, no one can accurately predict the trajectory and impact that blockchain-enabled applications can have on development practice in terms of enabling development workers and organizations to overcome new challenges or even achieve better developmental outcomes.

Currently, even if we cannot predict its outcomes till the technology becomes more mature, we argue that we can still make sure that blockchain use cases experimented by the development community are properly designed and implemented to live up to their promises. To do so, we argue that more research is needed to go beyond the hype-driven by the mainstream awareness behind the rapid rise of what we refer to here as the "let's blockchain it" movement which suggests that blockchain applications are superior compared to other alternatives in terms of their ability to deliver development outcomes.

Researchers, experts, and resource persons at the frontlines of innovation for development are called upon to develop actionable toolkits and toolboxes. Providing individuals and organizations with tools and approaches to guide their efforts step-by-step can not only yield sound use cases of blockchain enabled solutions for sustainable development, but also break the hype-cycle for blockchain to maintain its reputation and live up to its promises.

In this paper, we aim to add our contribution to the ongoing reflections within the international development community regarding the use of blockchain-based applications, in the practices of Islamic finance and circular economy, to solve specific development challenges and accelerate the achievement of the Sustainable Development Goals (SDGs). To do so, we first provide an overview of blockchain technology, looking at its mechanics and dynamics, at how it evolved, the different types of blockchains, and what are the possibilities for using blockchain-powered solutions to solve some of the most pressing development challenges we are facing today.

Similarly, we shed the light on the "Agenda 2030" for sustainable development, the implementation gaps, and the challenges ahead to meet the global goals by 2030. After that, we explore real-life case-studies of blockchain experiments, highlighting some of the 
areas where blockchain-enabled solutions may drive disruption, in ways that could yield huge development dividends and accelerate the SDGs with a special focus on Islamic finance, and circular economy. We conclude by highlighting the promising potential of blockchain technology to deliver development outcomes, while at the same time pointing the gaps that should be addressed for it to deliver its transformational impact.

\section{Blockchain in simplistic terms}

To avoid using the crypto jargon behind blockchain, a simplified way of describing it is to present it as the technology that enables consumers and suppliers to connect without the need for a trusted middleman to conduct transactions, removing thus the need for having a third party factored into the equation (Hutt, 2016). Technically, a blockchain can be explained as a sort of a database that is shared across a network of computers. One key difference with blockchain is that a database is centralized, while blockchain removes the need for a database administrator (Schlapkohl, 2019). It is similar to making thousands of copies of a spreadsheet and sharing it within a network including many computers, and that spreadsheet is regularly updated by the network (Rosic, 2016). Transactions are kept secure by using cryptography on a decentralized database that anyone in the network can monitor (Hutt, 2016).

Records on a blockchain can be any type of information, blocks are formed by bundling records, and chains are made by linking blocks together. Records provide transaction details and include a digital signature of the parties involved in the transaction, these details are then checked by the computers in the networks called nodes, following which the accepted records are added to a block (Murray, 2018). Each block has a code called a hash, these are strings of letters and numbers generated by mathematical functions. A block also contains the hash of the previous block in the chain. Once a block is added to the chain, the hash codes connect the blocks in a specific order (Murray, 2018). 
Figure 1: How did blockchain evolve over time?

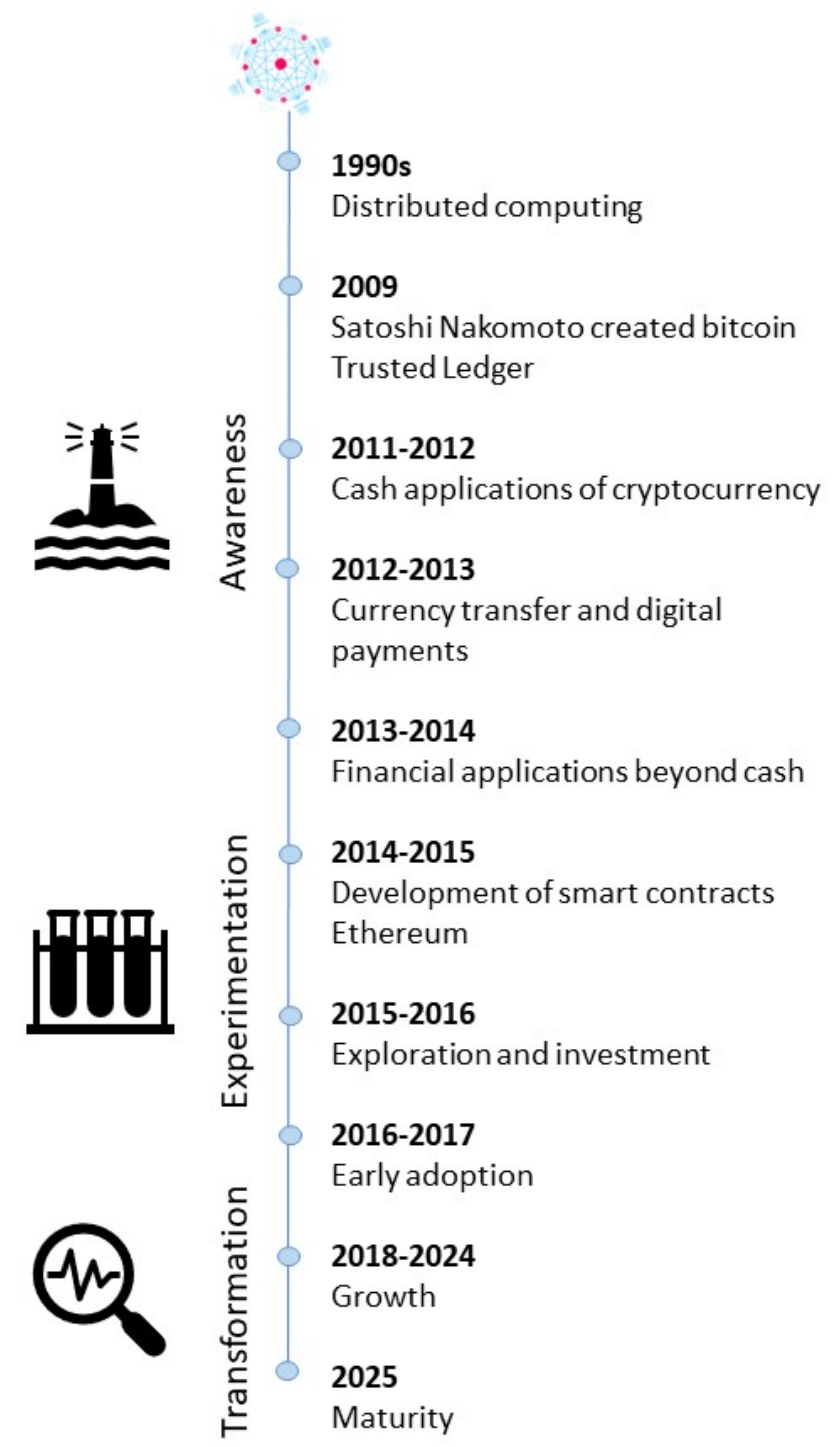

Source: Authors based on data from (Accenture, 2015), (PwC, 2017), (Capgemini, 2018)

Another way to visualize this process is the following: one person has a spreadsheet on his computer, while two government accountants have the same spreadsheet on their computers as well. Now, every time you make a transaction you send an email to inform each one of them, they both rush to check, the first to get the job done hits a reply-all button attaching evidence showing that the transaction is valid to get paid a salary. If the other accountant agrees all spreadsheets are updated. In this illustrative example, the person with the spreadsheet is the node, the spreadsheet is the ledger, the accountants are 
the miners, the salary is a token or cryptocurrency, the attachment is the Proof of Work, and the whole process is powered by blockchain technology (Deloitte, 2019).

Unlike centralized networks, a blockchain is a database with no Master. Computers or nodes willing to join the network and add blocks to the chain will have to pass tests dubbed consensus models, during which new members are required to prove themselves (Murray, 2018). For instance, a proof of work is about nodes demonstrating that they have solved an increasingly complex computational puzzle, this process is called mining. Miners invest huge computing powers and rewarded in exchange for their work by tokens or cryptocurrency such as bitcoin. Now, any change to the original information recorded, will generate a new hash, that breaks the chain, and a potential hacker will have to recalculate the hash for the next block in the chain and so on which requires a huge computing power (Murray, 2018). With blockchain technology, no single entity controls the data, no one can override it and can be independently verified, making it virtually impossible to hack (SelfKey, 2020).

\subsection{A quick dive into blockchain technology}

Blockchain can be used for any transactions of values such as money, goods, and properties with its use cases seemingly having a limitless potential (Hutt, 2016). It is an open-source technology that excludes the traditional third parties to rely on collective verification, thus offering a great alternative in terms of costs, traceability, security, and

speed. When two financial entities such as banks receive a request to transfer money from one account to another, they have to update the balances of their respective customers. This costly and time-consuming coordination and synchronization exercise can be simplified on a blockchain by using a single ledger of transactions reflecting a single version of records instead of two different databases (Mougayar, 2016). But blockchain applications can be much broader than just finance, as the digital-physical gap is closing the technology is steadily growing to encompass a myriad of use cases (Deloitte, 2019). Blockchains can be designed either as private or public, while decentralization remains a common denominator to both forms, there is a key difference in the level of access granted to participants (SelfKey, 2020). 
In the case of a public blockchain, participants are typically encouraged to join the network through an incentivizing mechanism such as the case of Bitcoin (Jayachandran, 2017). Anyone can join the network, decentralization is pushed to the fullest extent (SelfKey, 2020). On the other hand, private or permissioned blockchain, are closed networks where participants face restrictions in terms of who can write data and who can read it. Hence, while public blockchains maximize the anonymity, permissioned blockchains know the identity of its participants and determine which information they should or should not have access to (Massessi, 2018).

While perceptions suggest that public and permissioned blockchains are competing with each other, they have different offerings and could be rather complementary in terms of the solutions they offer (Massessi, 2018). While public blockchains offer high security, an open environment, anonymity, and no restrictions, private blockchains on the other hand prioritize full privacy, high efficiency, and stability. We can argue that permissionless blockchains empower the user by pushing transparency and decentralization to their full extents, while permissioned blockchains empower enterprises instead of individual employees (Anwar, 2020). The convergence of public and private blockchains is expected to pave the way for virtual ecosystems where a wide range of players can collaborate in a secure and auditable way (Deloitte, 2019). Then, which blockchain is better for which applications? Indeed, public and private blockchains have distinct use cases.

In general terms, public blockchains address business to consumer scenarios while private blockchains are more applicable to business to business relationships with some shared infrastructure between businesses (Massessi, 2018). The transparency and security features of public blockchains make it more suitable to develop blockchain-enabled solutions serving larger communities where trust is a key concern (SelfKey, 2020). It is a viable option in situations where all users should be treated equally and when the protection of users' anonymity brings an added value to the solution (Massessi, 2018). There are however some concerns whether confidential data should be recorded on a public blockchain assuming the encryption could be hacked one day (SelfKey, 2020). For 
instance, anyone should be able to own cryptocurrency like bitcoin or Ethereum, having role-based access would defeat the purpose in this case (Massessi, 2018).

In the world of private blockchains, there are quite opposite concerns, since the players are reluctant to publicly share their business data. This is more appealing to financial institutions and corporates so they can know and predetermine who has access to what (SelfKey, 2020). The downside though is that trust comes down to the credibility of the authorized nodes, besides a relatively higher vulnerability to malicious attacks (SelfKey, 2020). As blockchain technology keeps evolving, hybrid solutions could perhaps offer the best of both options by bringing together trust and security alongside efficiency and speed (SelfKey, 2020). Giving the current momentum in adopting blockchain applications across a large spectrum of industries, blockchain technology can only gain in popularity as the world entering the uncharted territories of a new normal in the post-COVID-19 era where technologies are poised to play an extremely important role in redefining business as usual ${ }^{1}$.

Figure 2 shows the types of platforms used by blockchain projects based on 71 entries listed in the Blockchain Impact Ledger which uses the SDGs to breakdown listed projects into impact areas (Goldstein \& Tillemann, 2020).

Figure 2: Types of blockchains used by blockchain projects for social impact

${ }^{1}$ One may see some of the related works of authors as follows in the references: Aysan, A. F. \& Bergigui, F. (2020), Aysan, A. F., Bergigui, F. \& Disli, M., (2021a), Aysan, A. F., Bergigui, F., \& Disli, M. (2021b) and Aysan, A. F., Demirtaş, H. B. \& Saraç, M. (2021). 


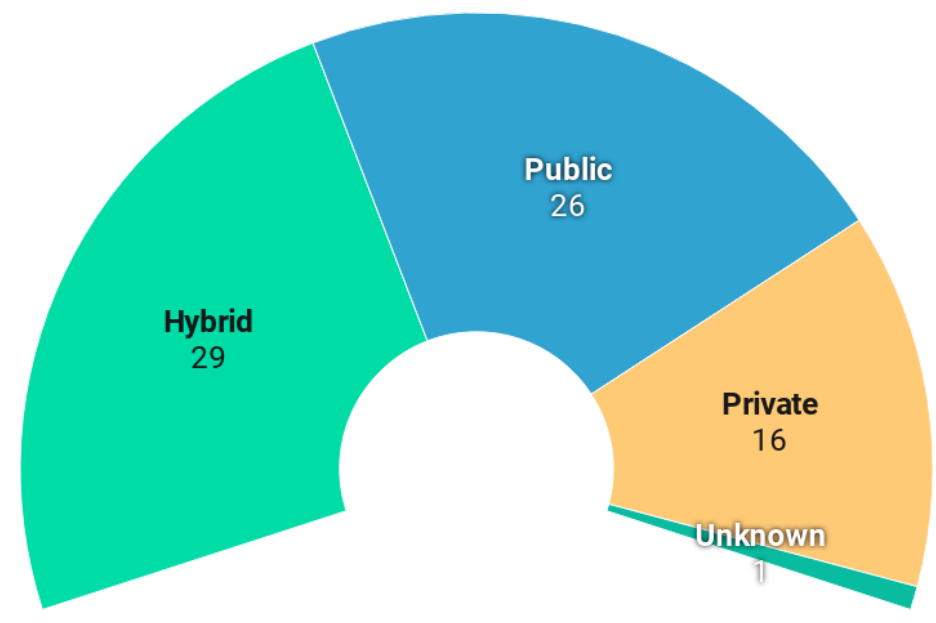

Source: Created by the authors based on data from (Goldstein \& Tillemann, 2020)

There is a myriad of platforms to develop blockchain applications, project managers need to do their due diligence by navigating variables from the type of blockchain needed, popularity of the platform, scalability requirements to smart contracts (Toshendra, 2020). These platforms use different types of networks, consensus algorithms, and programming languages. Ethereum and Hyperledger remain one of the most popular platforms (Malhotra, 2020). In terms of programming languages, $\mathrm{C}++$ and Go are among the top used by programmers for blockchain-related projects (Deloitte, 2017). Ethereum backed projects on GitHub for instance rose from just 3 in 2013 to 9970 by mid-2017 covering a wide range of applications such as identity management, crowdfunding platforms, remittances, and new cryptocurrencies (Deloitte, 2017).

\subsection{Smart Contracts}

A key feature of blockchain technology is undeniably its ability to accommodate smart contracts. Smart contracts are agreements between two parties recorded as computer code on the blockchain, which is automatically activated when the conditions agreed upon in the agreements are met (BitDegree, 2020). In other words, assets or currencies are transferred into a program, which runs a code that automatically validates the conditions to decide on asset allocation. What smart contracts do is that they take intermediaries out 
of the equation, as they are stored on the blockchain and transactions are automatically executed, there are no trust-related issues (CoinTelegrap, 2016). In simplified terms, it works like a vending machine. By inserting the right amount of cryptocurrency into the smart contract, the asset be it a house ownership right or a driver's license drops into the designated account (CoinTelegrap, 2016).

There are virtually endless possibilities to use smart contracts for financial services, trade, healthcare, insurance, fundraising to virtually everything. For instance, by using smart contracts in the healthcare industry one can securely transfer data without the need for transiting via a third party. Patients can have control over their medical data, they can get paid for it or simply choose not to sell it (Encrypgen, 2018). When smart contracts are used to write voting transactions on a blockchain, a token will be sent to the address representing the winner once the vote is over (FollowMyVote, 2012).

While smart contracts can be a miraculous solution to save costs, gain speed and disintermediate transactions, there are also questions about the future in terms of their impact on jobs that will be replaced and not needed anymore in the digital age of blockchain.

\section{Understanding Trust}

Among blockchain enthusiasts who believe that blockchain-powered solutions can be used to solve virtually anything, and crypto-skeptics who argue that the bubble driven by the overhype may fail to deliver its promises and burst, we believe that one of the key elements, worth examining is the notion of trust. Considering the multidisciplinary definitions of trust, the rising complexity of networks in modern societies drives a composite trust that results from the interplay of features specific to a complex network (Cho, Chan, \& Adal1, 2015). In the digital age, blockchain may shift the trust from analog to digital. Nevertheless, blockchain may not replace trust but rather become the future of trust, depending on how fast the transition can be from trusting legacy trust intermediaries to digital trust in the form of blockchain-backed crypto-trust (Blasingame, 2019). What blockchain does, is to shift from trusting people and institutions to trust technology from 
the cryptography to the software, the network, the computers, and the people making the system work (Shein, 2019).

In one research, a blockchain-backed model of trust was proposed in the field of higher education, to enable training institutions to adapt curricula to match the specific needs as endorsed by employers (Lizcano, Lara, White, \& Aljawarneh, 2020). In another research, a trust model was proposed for blockchain-backed identity management, it is based on a numerical trust metric as an independent basis to characterize assurance levels (Grüner, Mühle, Gayvoro, \& Meinel, 2018). In the case of tourism crowdsourcing platforms, false data can distort realities hence the rising interest in trust and reputation modeling to assess the quality of the information outsourced from the crowds and its trustworthiness. Blockchain can associate contributions to contributors and make transactions reliable, which makes the case for blockchain-backed built-in trust and reputation modeling within crowdsourcing platforms to enhance trust between consumers and service providers (Velosoa, Leal, Malheiro, \& Moreira, 2019).

A recent book on blockchain and the new architecture of trust examined blockchain as a new form of trust by looking into its blend of social, technical, and legal features upon which the architecture of trust is built. Trusting a blockchain-enabled solution goes beyond the integrity of transaction ledgers and audit logs, and entail effective governance mechanisms which operate in decentralized environments (Werbach, 2019). Indeed, there are several tension points between law and blockchain, the latter may remove mechanisms for legal enforcement, create barriers to prosecute criminal activity, and can be less accurate in dealing with human variables when compared to courts and lawyers (Werbach, 2019). Yet, blockchain can also offer new opportunities to lawyers by removing the traditional frictions in transactions that are algorithmically executed using smart contracts (Werbach, 2019).

Critics argue that verification cannot replace trust, that institutional trust is still needed as well as governance outside the system to override the rules and introduce changes when they are required. Furthermore, several questions persist as to whether the trust intermediaries of the novel crypto architecture are better than their predecessors, the 
possibilities of abusing trust under in such a new system, and whether the benefits of public blockchains outweigh the issues they bring (Shein, 2019). As there are still more questions than answers, we argue that the future of blockchain technology may well depend on the viability of its new architecture of trust. Whether or not it will become the future of trust to replace or co-exist with traditional trust intermediaries, academic discussions and experimentations will continue exploring trust models in the crypto-space to bring-in some of the critical answers.

\section{The Sustainable Developments Goals (SDGs)}

The Sustainable Developments Goals (SDGs) replaced the Millennial Development Goals (MDGs) as the leading global development framework since their inception in 2015 to 2030. In contrast with the truncated approach of the MDGs which were not achieved overall by 2015 despite the tremendous progress made, the 17 goals and 169 targets are universal and represent an ambitious agenda for sustainable development spanning social, economic and environmental considerations all over the world uniting both developed and developing countries to raise a historical challenge of delivering on their ambitions by 2030 while leaving no one behind.

Figure 3: The Sustainable Development Goals (SDGs)
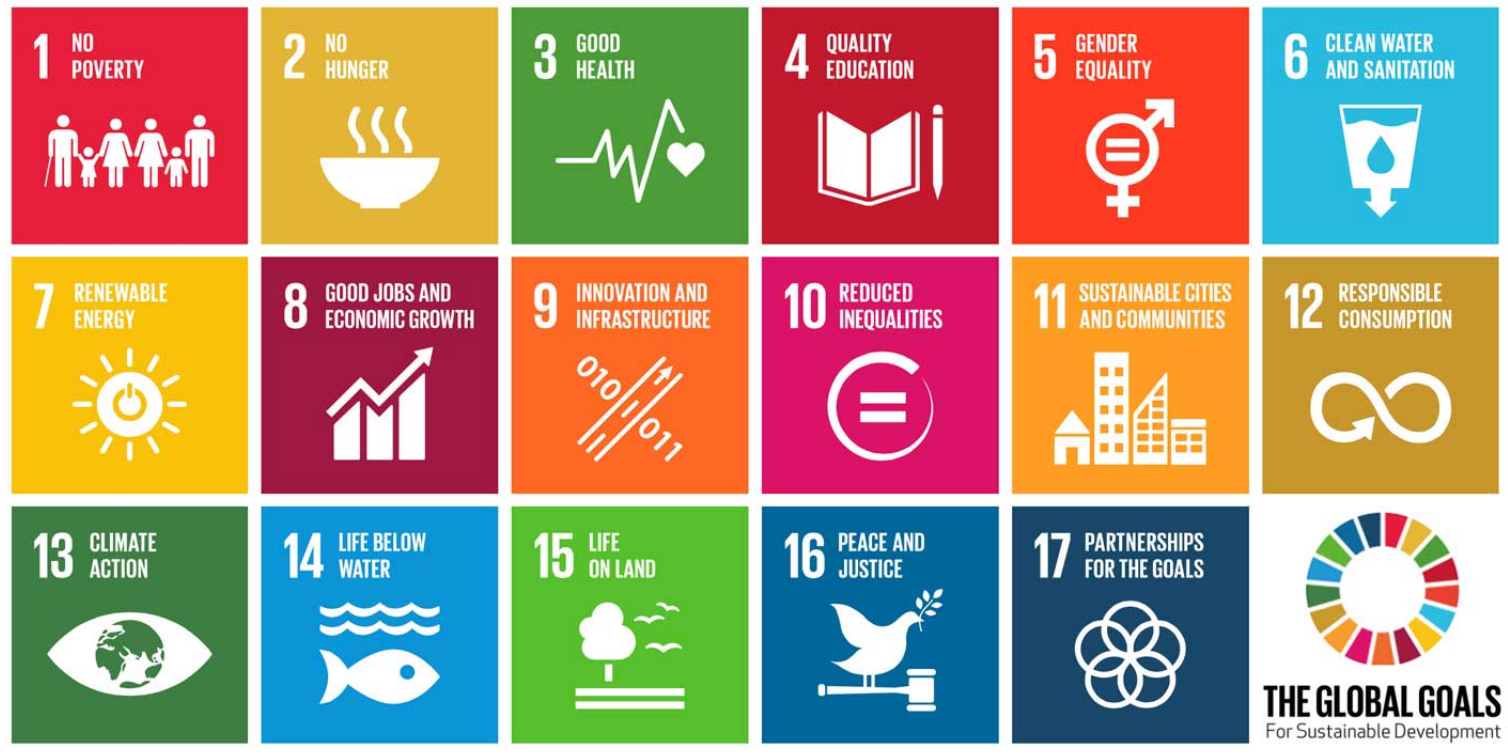

Source: (United Nations, 2020) 
While recognizing the great efforts made and the significant progress achieved worldwide as reported by countries in their national voluntary reviews (UN DESA, 2020), there is no country in the world on track to achieve all the SDGs by 2030 (Sachs, Schmidt-Traub, Kroll, Lafortune, \& Fuller, 2019). We can argue that the international community has so far failed to create the conditions needed to achieve such an ambitious agenda. The multilateralism canopy which used to lay the foundations for the international community is shrinking driven by rampant unilateralism and trade wars (Ghosh, 2019). In an increasingly multipolar world, this could be explained by the worrying trends in the global economic architecture and patterns in trade and capital flows that are fueling inequalities. From intellectual property rights, the privatization of natural and social assets, market monopolies to corporate tax avoidance, regressive indirect taxations to fiscal austerity measures (Ghosh, 2019).

Before the new Coronavirus disease, the funding gap to meet the SDG targets by 2030 was estimated at US\$ 2.5 trillion annually (Burgess \& Turner, 2019). To bridge the gap in development finance needed for the SDGs, there is a need to attract private capital flows and consider innovative and scalable approaches (Runde, Metzger, \& F. Abdullah, 2020). This is a key area where blockchain-enabled applications can play a vital role in areas such as remittances, impact investing, crowdfunding, and Islamic finance.

Uncertainties under a new normal may indeed derail current efforts to meet national global targets (Aysan et al. 2019). Initial assessments are already showing that the Coronavirus pandemic is affecting all the SDGs from loss of income drowning entire segments of societies below poverty lines, increased levels of violence against women, reduced commitment for climate action, to backlashes against globalization (UN DESA, 2020). The Preliminary findings from a recent survey of the public opinion on the impact of the pandemic on achieving the SDGs by 2030, suggest that the majority of participants with 43.6\% believe that the crisis will both accelerate and slow down the SDGs in the same proportions, while another $36 \%$ see a negative impact and are of the view that on the long run it will only slow down the SDGs (Lafortune, 2020). In order not to derail the current momentum for meeting the SDG targets by 2030, countries will need to implement coordinated packages that support financial stimulus, concessional finance, debt relief, 
market liquidity, resilient infrastructures, crisis prevention, social protection systems, trade and supply chains (Subhanij \& Hasannudin, 2020).

\section{Can blockchain offer superior solutions to achieve the SDGs?}

An overview of initiatives using Distributed Ledger Technologies (DLTs) suggests that blockchain could transform the ambition for good into tangible results (Kewell, Adams, \& Parry, 2017). Blockchain can be an enabling technology to develop sustainable and secure solutions, this can be explained by its ability to enhance operational efficiency in global partnerships, but also to deliver the key functions of transparency, traceability, accountability, cyber-resilience to fulfill the SDGs (Fraga-Lamas \& M. Fernández-Cara, 2020). While there is a growing interest in blockchain technology, there are not many examples in the literature explaining how blockchain is operationalized in concrete terms (Nikolakis, John, \& Harish, 2018). There are also technological barriers facing the adoption of blockchain such as in the field of sustainable supply management that can be technical, inter-organizational, intra-organizational, or external (Saberi, Kouhizadeh, Sarkis, \& Shen, 2018).

The notion of blockchain for good in reference to the SDGs can be questioned through the lenses of the existing cautionary literature. It is still unclear whether DLTs can deliver a better society that is more democratic, inclusive and sustainable, or rather becomes another tool deployed by organizations and authorities for control and surveillance purposes (Kewell, Adams, \& Parry, 2017). Some of the most promising use cases for a successful implementation of blockchain-enabled solutions were found in the areas of affordable and clean energy under SDG 7, and in the areas of responsible consumption and production under SDG 12 (Shermin, Tatjana, Wildenberg, \& Rammel, 2019).

Despite a noticeable increase in blockchain-related research, little attention was given to the issues of sustainability and open innovation while developing academic and commercial solutions, most of which are still at their early stages (Fraga-Lamas \& M. Fernández-Cara, 2020). The usefulness of blockchain-powered solutions for instance to increase financial inclusion can be negatively affected by the absence of protocols and definitions, which hinders its ability to make a significant difference (Danho \& Habte, 
2019). Similarly, for blockchain to fulfill its promise for instance to enhance sustainability within global value chains, there is a need to establish proper safeguards (Nikolakis, John, $\&$ Harish, 2018). More research is needed for a better understanding of the extent to which DLTs can be deployed and their ability to deliver the SDGs purposes (Kewell, Adams, \& Parry, 2017).

While virtually there is an undeniable potential for blockchain use cases to accelerate achieving each one of the SDGs, there is also a huge lack of data to truly assess the contribution of blockchain to sustainable development. Unlike its financial and commercial applications, blockchain-enabled solutions for social impact remain relatively understudied (Goldstein \& Tillemann, 2020). In the absence of aggregate data to build the body of knowledge about blockchain use cases for the SDGs, organizations, and individuals implementing blockchain projects for social impact may not be able to learn from it. We argue that such knowledge is indeed critical to extract good practices, lessons learned, share experiences, and catalyze join efforts towards reaching economies of scale and perhaps pave the way to functional blockchain ecosystems.

Several initiatives are working to fill in the information chasm within the arena of blockchain for sustainable development by building online databases of blockchain projects such as the Positive Blockchain database reportedly the largest with more than 850 impact blockchain projects (PositiveBlockchain, 2020), the Blockchain Impact Ledger (Goldstein \& Tillemann, 2020), and the Canonical Blockchain List (Brand, 2018).

While many agree on the promising potential of blockchain technology, critics highlight its early stage of development and the need for a better understanding of what can be done and what cannot be done with blockchain, when to implement it, which underlying ethics to consider, and how to monitor and evaluate its system-wide improvement and measure its impact on the international humanitarian and development practice (Joost \& Andrej, 2018). Other critics emphasize the absence of appropriate data and evidence to support claims throughout the chain of results from outputs, outcomes to the impact of blockchainbacked solutions. The same applies to lessons learned and practical insights which remain understudied compared to other emerging technologies (Vota, 2018). 
At the core of the relationship with donors and partners funding the SDGs are the imperatives of trust and accountability. While both can be achieved to some extent via traditional reporting mechanisms, such practice can surely benefit from appropriate technological innovations. Against this backdrop, the adoption of blockchain technology within the international development community should not be solely approached through the lenses of testing new technological gadgets. The ongoing trial and error experiments of blockchain technology should also consider blockchain standards such as those being developed by ISO TC 307 (Ryan \& Horner, 2019). A more transparent and efficient international development is critical to sustaining healthy levels of trust between donors, governments, businesses, multilateral organizations, and civil society organizations. It is also necessary to maintain the reputation of blockchain technology (Ryan \& Horner, 2019). Blockchain is not a risk-free technology and has its own set of transparency and cybersecurity risks, regulatory challenges, and interoperability problems resulting from fragmented digitalization (ADB, 2019).

Deploying blockchain-backed solutions comes with its own set of challenges from talent shortages, to scalability concerns, regulatory issues, governance, and change management concerns (Ranjan, Hung, Mohindroo, \& Vignesh, 2019). The blockchain deployment toolkit released by the World Economic Forum on April 2020 for instance, may provide some of the very much needed tools needed in the blockchain space to guide organizations and individuals in their journey to galvanize more responsible deployment, de-risk adoption by the early movers in their industries, while also carefully considering unintended consequences (WEF, 2020).

The map in figure 4 shows a breakdown by region of the cumulative numbers of the SDGs to which blockchain projects for social impact contribute based on 71 entries listed in the Blockchain Ledger Impact database. This visualization suggests that East Asia and Pacific comes first as the region where blockchain projects contribute to the largest number of SDGs (Goldstein \& Tillemann, 2020). It's followed by North America, Europe, and Central Asia, Latin America and the Caribbean, Sub Saharan Africa, the Middle East and South Africa, and South Asia. While the map itself offers much-needed insights into the dynamics of the contribution made by blockchain-enabled solutions to the SDGs, it is only 
based on a limited number of blockchain projects for social impact $(\mathrm{n}=71)$ and naturally falls short of providing the full picture. This shows that blockchain-powered solutions remain largely understudied, which stresses the need for reliable sources of data to study how blockchain projects deliver or not, social impact on the ground (Goldstein \& Tillemann, 2020). Such insights are critical learning tools for organizations and individuals alike in an exciting but demanding journey to develop blockchain-backed solutions for social good. 

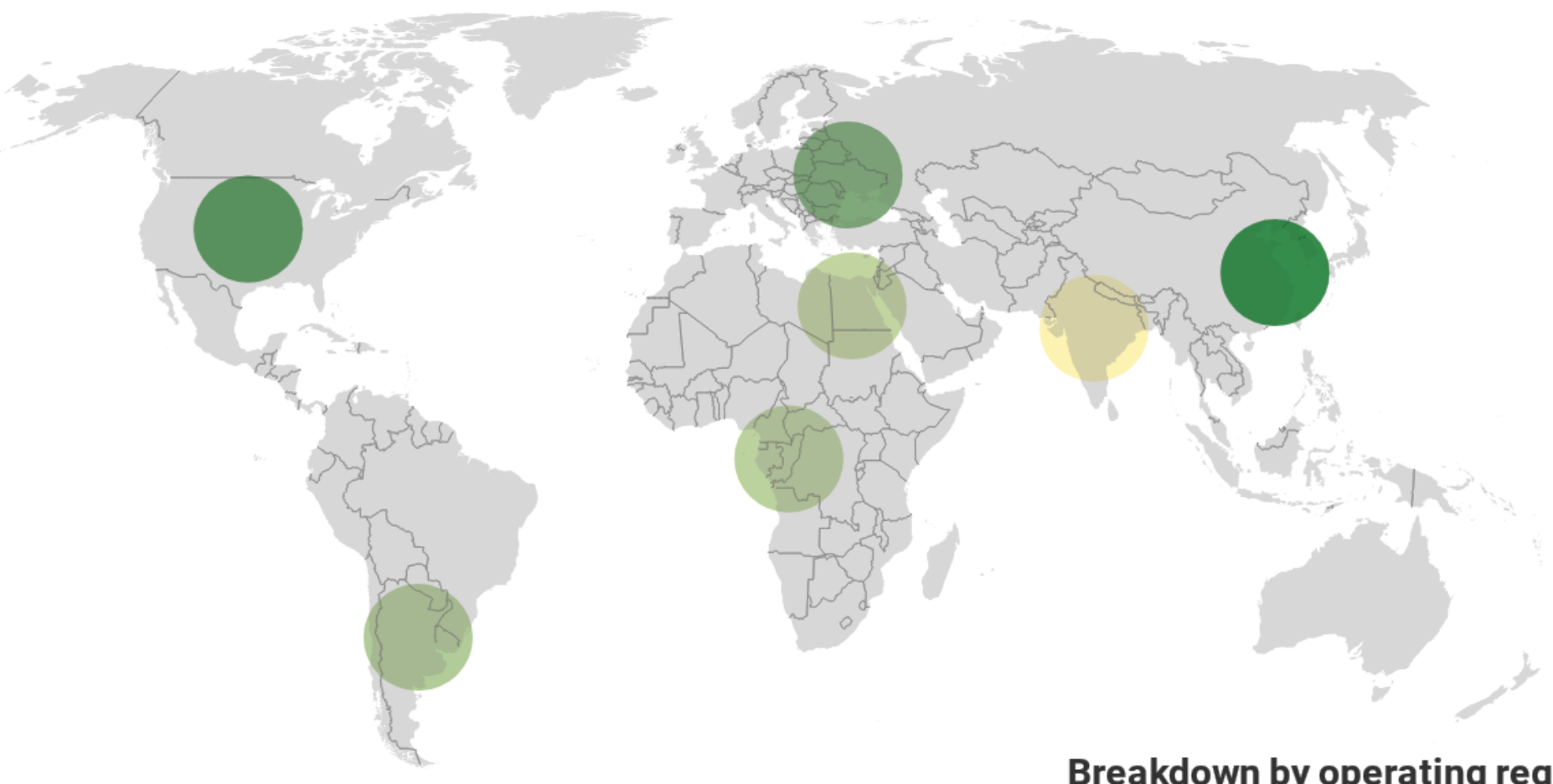

Breakdown by operating region

30

40

50

60

Figure 4: Map showing the contribution of blockchain projects to the SDGs per region

Source: Created by the authors based on data from (Goldstein \& Tillemann, 2020) 


\section{Blockchain and the SDGs in the age of COVID-19}

The year 2020 is a symbolic landmark within the international development community marking 10 years to achieve the ambitious sustainable development agenda by 2030. As the world declared war to the invisible enemy, the uncertainties and volatilities that followed are posing serious risks to sustain the momentum in meeting the SDG targets by 2030 as the world priorities may shift towards managing the pandemic. At the very time where financial markets were tumbling, borders shutting down, people panic buying and millions losing their jobs, development financing may be repurposed to solve pressing domestic issues at home first, as countries inject stimulus packages to revive their economies. During unusual times, unusual solutions may be required, disruptive technologies may be needed more than ever before.

As the world is walking into the uncharted territories of the post-COVID-19, and as disruption waves are building and breaking on the shores of the international development practice as we once knew it, business-as-unusual will undeniably become the new normal. With that in mind, there is a need to rethink the architecture of international development as the current practice might become obsolete before we know it in the race to the unknowns. So how do we adapt to a new normal? With initial estimates indicating that the Coronavirus disease will cost the global economy around US\$ 1 trillion (UNCTAD, 2020), disruptive solutions are needed in the face of a looming socio-economic crisis to avoid reversing the hardly achieved development gains during the recent decades. Luckily, the new normal is not only a matter of uncertainties and volatilities driven by skepticism, fear, and fragility, it is also an era-defining moment of opportunities.

In the aftermath of the Coronavirus disease, we are witnessing a historical opportunity to reboot our systems and rebuild our economies based on the triple bottom line of social, economic, and natural capitals. As we are rebuilding our economic systems, many questions remain however as to how we address inequalities, reverse the loss of biodiversity, or tackle the climate crisis. While there are no easy one-size-fits-all answers, we argue that we cannot solve an issue with the same thinking that created the issue. For instance, to embrace a true sharing economy we do not have to redistribute wealth once it 
is created but instead pre-distribute productive assets to the crowds upfront through a decentralized system.

Tech trends during the pandemic provided a pre-taste of what would a new normal look like. Online shopping, contactless payment, remote working, e-learning, digital health, eentertainment, data-based supply chains, 3D printing, 5G, robotics, and drones are all part of the rich landscape of digital readiness (Xiao \& Fan, 2020). Similarly, some technologies are expected to boom in the aftermath of the pandemic, this is the case for example of data-enabled health care, digital supply chains, e-commerce, digital collaboration, and entertainment (Ruokonen, 2020).

The current economic and development landscapes suggest that disruptive technologies such as blockchain will play a leading role in defining and adapting to the new normal in the post-COVID-19 era (Banafa, 2020). As a consequence, we can safely assume that the blockchain technology will only gain further attention which will in return boost its adoption and growth making it perhaps the new internet of tomorrow, the internet of value.

\section{Use cases of blockchain-enabled solutions across the SDGs}

The digital wave of disruption is having a far-reaching scope with many blockchain applications currently testing the waters of Islamic finance. With its assets reaching $\$ 2.5$ trillion in 2018, a 3\% increase compared to 2017 (ICD, 2019), the Islamic finance industry is being shaped by Financial-technology or Fintech. Scholars and regulators alike are exploring the potential of crypto-assets and blockchain-powered digital platforms. Giving its multiple applications designed for Islamic social finance, blockchain has the potential to lay out the foundations for a booming industry while accelerating the achievement of the SDGs (ICD, 2019).

Blockchain can be harnessed in Islamic finance in different ways such as smart contracts which can be used for managing profit-sharing agreements and partnerships, the verification of Islamic financial transactions for banks and customers to avoid conflicts and increase transparency, and the integration with mobile technology in countries lacking banking infrastructure (OConnell, 2019). While Islamic FinTech faces the challenge of 
blockchain-related "sharia" compliance, Islamic financial institutions can increase efficiency, transparency, and customer satisfaction by adopting FinTech (Rabbani, Khan, $\&$ Thalassinos, 2020).

For instance, the Zakat ecosystem is facing several challenges that are related to reporting, transparency, and traceability. From Zakat (Blossom, 2018), to charitable donations (KryptoPal, 2018), halal certification (Mirchandani, 2018), and Sukuk transactions in the financial markets (Al Hilal Bank, 2018), the winds of blockchain-based technological innovation are blowing and driving substantial change in the Islamic finance industry, in particular with millennials (ICD, 2019). The snowball is getting bigger and bigger.

In an attempt to tap into the unseized potential of the Zakat given worldwide which stands at $\$ 76$ billion, far below its potential of $\$ 356$ billion (DinarStandard, 2019), UNHCR's Zakat Refugee Fund was launched in September 2016 (UNHCR, 2019) and so far \$38.1 million has been raised, helping about 111,209 refugee and IDP families (approximately 648,476 individuals) in Yemen, Lebanon, Iraq, Egypt, Jordan, Mauritania and Bangladesh (UNHCR, 2019). The potential of Zakat combined with its ability to contribute solving some of the most pressing issues such as the refugee crisis, paves the way for blockchainbased applications to ensure the much-needed accountability and transparency in the Zakat industry. By building a decentralized social impact network on the blockchain, social organizations can use smart contracts to capture end-to-end transactions and ensure that donor's impact is independently verifiable and accessible to everyone.

Blossom Finance, uses Bitcoin to provide microfinance services to entrepreneurs and small businesses (Blossom, 2020). During the month of Ramadan, Blossom reportedly offered a free Zakat via Blockchain service, the transfers are made to a designated wallet and used to support the poor in central Java and Sumatra (Blossom, 2020).

In the Halal certification industry, giving its vulnerability to fraud, blockchain-backed solutions are being experimented. KT, a telecom company, and partners are working to establish a Halal Certification Platform which will issue certificates on the blockchain while allowing customers to use QR cods on their products to verify their status (Wood, 
2019). OneAgrix, a trading marketplace, provides a B2B platform using a blockchain ledger to trace halal ingredients and authenticate halal certificates (Whitehead, 2019).

With the emergence of circular business models across global supply chains (WEF, 2014), and while circular economy practices can contribute to a wide array of SDGs, such contributions may be particularly significant for SDG 6, SDG 7, SDG 8, SDG 12, and SDG 15 (Schroeder, Anggraeni, \& Weber, 2018). We will examine how blockchainbacked solutions do also contribute to these SDGs in a transition towards a circular economy.

\subsection{Sustainable water management}

Blockchain-based schemes can transform the future of water management and trade by recording transactions between parties to boost transparency in times of water scarcity, crises, and mistrust towards governments and corporations. Blockchain platforms can also fund water treatment projects, while waste management systems powered by blockchain can increase efficiency and transparency. The technology can also enable water trading, smart meters, monitoring of rainfall and water quality in catchment areas, and automated crop insurance during droughts (WEF, 2018)

Bundling blockchain-based solutions with other digital water technologies such as IoT, $\mathrm{AI}$, and big data can bolster smart water management systems using sensors to collect valuable data about water quality, pressure, leaks and pipe bursts and trigger adequate management responses. Such innovations do not only have the potential to optimize the use of water resources, but also nudge rational behavioral changes among consumers. Nevertheless, early movers will have to overcome the high start-up cost, secure the expertise needed, and comply with health standards and regulations.

Waterig, an off-grid network powered by blockchain and IoT aiming to facilitate the exchange of surplus water and food, proposes a water production solution through its installations by capturing atmospheric water, purifying grid water, collecting rainwater and also by treating free water for irrigation purposes. It also harvests renewable energy from solar, eolian, underground, and waste sources which can be fed into water production 
and processing or used to power nearby vertical food farms. The system broadcasts water and food data on the blockchain to track and monitor water usage and quality (Suen, 2020). This innovation targets participants such as hub micro-owner, water token traders, vertical farms operators, mainly benefiting people with limited mobility to acquire water and food such as the elderly. The pilots can be financed by crypto-tokens from local microinvestors, the token signifies micro-ownership and can be freely traded on a dedicated platform (Suen, 2020).

Civic Ledger, specialized in data-driven solutions for the public sector, was tasked to examine the reluctance of some irrigators to trade water in the Australian water markets. A blockchain-backed solution dubbed Water Ledger was proposed in the feasibility study offering a digital peer-to-peer water entitlement registry and trading platform. While it simplifies and automates water trading, it also improves transparency related to water prices and volumes while enables non-traders to offer unused water allocations (Civic Ledger, 2020). WaterChain, a blockchain-backed water funding platform, aims to open up investments in clean water projects, investors can by WaterChain tokens to hold a stake in specific water projects and get dividends. It is also exploring ways to process payments and blend blockchain with IoT to track the usage and quality of water (WaterChain, 2018).

\subsection{Sustainable energy}

Giving its complexity the energy sector needs a great deal of intelligence and transparency which provided a fertile ground for new business models to evolve and emerge driven by blockchain technology, including through power trading and financing for renewables (IRENA, 2019). Blockchain can be a true disruptor for the energy industry which remains despite its technology-rich landscape a complex and costly transactional ecosystem (Deloitte, 2018). Its use in the energy market is predicted to reach record high driven by a surge in interconnection and digitalization raising security concerns of grids and networks. Most of the blockchain energy projects are building peer to peer energy markets, with many countries reaching energy parity, individuals producing their energy will be able to trade it with their neighbors and peers. 
Other blockchain applications are used to redesign the wholesale electricity distribution by supplementing retailers and allowing users to connect directly to the grid, to securely manage energy data, support commodity trading, share information and data among utility providers, facilitate and track the trade of gas and oil, allow regulators access transparent data for reporting and compliance, reduce and track carbon emission and to reward the adoption of renewable energy.

In Australia, the City of Fremantle is using blockchain-backed solutions to power renewable solar energy systems through the RENeW Nexus project. In its trial the platform enabled neighbors from about 40 households to trade the excess in rooftop produced solar energy, providing real-time tracking of energy transactions among the participants (Power Ledger, 2020). In Estonia, WePower tokenized national energy production and consumption data in the blockchain. A total of 26.000 hours and 24TWh of energy data was uploaded to a blockchain-backed platform creating 39 billion smart energy Tokens. By linking smart contracts with power grid data, the tokens represent selfsettling power purchase contracts of $1 \mathrm{KWh}$ which can be traded and liquidated in the local energy wholesale market (Invest In Estonia, 2018).

\subsection{Reducing inequality}

Blockchain can play a vital role as a core enabling technology for the sharing economy which has the potential to rebalance wealth distribution between and within countries based on pre-distribution of productive assets in contrast with wealth re-distribution once inequalities have already occurred (Berggruen, 2018). In other words, the ability of blockchain to transfer wealth over the internet makes a strong case for a contemporary solution to enable a true sharing economy that is secure, efficient, and transparent (Avendano, Pico, \& Igunma, 2019).

By issuing Sharia-compliant Sukuk using blockchain, Blossom Finance and partners raised USD 50,000 using a profit-sharing structure and carrying a one-year maturity to expand financing to local entrepreneurs. Its impact investing platform is financing social impact projects using Ethereum smart contracts while ensuring an audit trail on 
transactions carried on at every step of the process (Blossom, 2019). Consumers can be also empowered to trace back the origin of their food supply. Food Trust is a blockchain platform that connects consumers with smallholder coffee farmers to trace coffee throughout the supply chain from the moment beans are picked (IBM, 2020). To tackle a changing climate and boost the resilience of rice farmers in Sri Lanka, Oxfam and partners are developing a blockchain-enabled micro-insurance platform to lower costs and enable rice farmers to access affordable insurance options (Aon, 2018).

\subsection{Sustainable consumption and production}

The current business model according to which goods and services are produced and consumed is facing unprecedented scrutiny driven by an increasingly conscious consumer base, the pressure on planetary boundaries and the devastating consequences of overproduction and over-consumption on natural equilibriums whether it is about climate change, loss of biodiversity and ecosystem services, besides damaging other assets of natural capital. A supply chain for a given commodity, for instance, may involve a dozen middlemen and brokers between the smallholders and the consumers while adding no significant value to the products or services supplied. Not only the consumers will end up having no information if the price they are paying is fair, but the smallholders will be missing all the value addition downstream of the supply chain. This is indeed one of the scenarios where blockchain-based solutions can come into play. In fact, by recording data and keeping it safe in a decentralized manner, it can increase transparency, renew confidence, and restore trust within peer-to-peer transactions (University of Canterbury, 2019).

A growing body of research conducted on sustainable production and consumption points towards the need to increase efficiency at the production stage while reconsidering consumption patterns. This entails considering technological improvements, generating reliable data for consumers to make informed decisions, which can influence consumption, distribution and pave the way for institutional changes (Bengtsson, Alfredsson, Cohen, Lorek, \& Schroeder, 2018). 
Swachhcoin, is a blockchain-based platform working to reinvent waste management through an integrated ecosystem of blockchain, Big Data, IoT, and AI. By using smart bins capable of recognizing and recording the type of waste the latter is turned into 20 different types of useful products such as electricity, precious metals, and timber (Gopalakrishnan \& Radhakrishnan, 2019).

\subsection{Solving the climate crisis}

To solve a disruptive climate crisis, one should consider disruptive solutions. In the climate change arena, numerous blockchain use cases are emerging to give an impetus to the much-needed climate action. The technology can be used to improve carbon emission trading, enable peer-to-peer renewable energy trading platforms, facilitate all sorts of financial transactions, and most importantly provide more transparency in the reporting of GHG emissions and the progress made in implementing the NDCs (UNFCCC, 2017). However, to truly unleash the potential of blockchain for climate action, more research is needed to design meaningful approaches according to which blockchain-enabled solutions can become part of the climate action landscape, experimentations at the crossroads of blockchain and climate change are expected to shed some light on good practices and lessons learned. The most promising use cases for blockchain in climate action were reported to be those related to registries and tracking, MRV systems, and access to clean energy and finance (CLI, 2019).

A blockchain-backed carbon trading platform created by IBM and Energy Blockchain Labs allows high carbon emitters to buy carbon credits from low emitters to comply with the applicable Government quotas (IBM, 2018). CarbonX, a peer-to-peer voluntary personal trading platform, operates by sourcing carbon credits and recasting offsets as tokens on the Ethereum blockchain, which are then distributed through a loyalty rewards program to offset the carbon footprint of products and services and allow its customers achieve carbon neutrality in their consumption behaviors (CarbonX, 2018). ClimateTrade, another blockchain-enabled platform is offering services from acquiring carbon credits to offset emissions, impact investing, and blended finance by allowing customers to invest 
in equity and generate revenues by funding climate change mitigation and adaptation projects (ClimateTrade, 2020).

Carbon market applications of the blockchain technology offer advantages ranging from high speed to immutable audit trails, lower transaction, and management costs and the traceability of emissions reduction (UNEP DTU, 2019). In a comparative study of 4 blockchain platforms, Ethereum blockchain stood out as the best benchmark for climate policy instruments which was attributed to its architecture and key features such as selfmade cryptocurrencies, limited operational costs, flexibility for programming and ease of use (Braden, 2019).

\subsection{Blue economy}

For the ocean's conservation and the sustainable use of our marine resources, it is necessary to ensure full traceability of the seafood supply chain by tracking the resource from ship to supermarket. This can be facilitated through the use of promising technologies such as radio frequency identification tags, DNA barcoding, or blockchain (WEF, 2017). By enabling transparency and traceability along the seafood supply chain, blockchain-backed platforms can empower markets and consumers to reward sustainable producers while flagging unethical practices (Cook, 2018). In the maritime shipping and logistics industry, disruptive solutions are pursued by maritime transport operators to reduce costs and ensure efficiencies (OECD, 2019). While global ocean governance instruments such as the UN Convention on the Law of the Sea (UNCLOS) are vital for the sustainable management of oceans and marine resources, they fall short in terms of policing and reinforcing the regulations they entail. Disruptive technologies can be the key to transparency and traceability (Scruggs, 2018).

Fishcoin, a blockchain-enabled data ecosystem approach to transform the seafood industry, offers an incentive for seafood harvesters to capture and communicate data in exchange for rewards such as top-ups for mobile data plans. As a consequence, the economic burden of data collection is shifted downstream to the supply chain by using tokens while ensuring traceability and transparency (Chase, 2018). WWF and partners 
initiated a blockchain-based project to tell the story of Fijian tuna fish. By assigning QR codes or sensor devices to assets, consumers can view the journey of the product they are buying using a smartphone application, and get to know the actors behind it from the fishermen to the plate (Cook, 2018). To trace Indonesian skipjack and yellowfin tuna from vessel to factory, fishermen send text messages to register the catch which results in an asset being issued on a blockchain and transferred as the fish moves along the supply chain (Leber, 2018).

\subsection{Green Economy}

The key feature to foster environmental sustainability relies on the ability of the blockchain technology to guarantee immutable and verifiable records of how biodiversity, natural resources, and ecosystem services were managed as a reliable alternative in the absence of trust and poor confidence in the existing environmental governance schemes.

The Earth Bank of Codes, a digital platform to map out the genetic sequences of biological diversity in key terrestrial and maritime biomes, works on registering assets on blockchain recording the origin of the resource as well as the rights and obligations associated with its utilization. Once the value is created through products and services derived from bioinspired innovations, benefits can be shared via smart contracts with the resource providers which will contribute to the conservation and the sustainable use of biodiversity (Earth Bank of Codes, 2018). To fight deforestation in the Amazon, GainForest empowers donors and caretakers to protect the rainforest through smart contracts. The way it works is that volunteer caretakers commit to ensuring that a forest patch is protected from deforestation and stake a voluntary amount which they can claim back in addition to a reward after the conservation period is over (Murtaza, 2019).

\section{Concluding remarks and discussions}

Blockchain can be visualized as this cryptographic book of truth upon which robust foundations of trust can be built. Coping with relentless technological advances is not an easy task, riding the wave of disruptive innovations such as the blockchain technology can be illustrated with climbing a mudslide raging down the mountain. More research is 
required to assess the true extent to which development workers are able or not to transform the promising potential of blockchain-backed solutions into tangible development results beyond the hype.

With blockchain experiments demonstrating disruptive solutions, the surge in recent years looking into an increasingly diversified pool of use cases to rethink a wide array of applications across the SDGs, combined with the progressive removal of some of the key barriers slowing its adoption at scale, are all encouraging signs of its maturation. Despite all the existing challenges and those yet to come, we can argue that the blockchain technology made it to the much-cherished pool of game-changers that have the power to disrupt our ways of thinking, those have undeniably become the tools for today's and tomorrow's business as unusual. Nevertheless, it is very important to distinguish between those cases where blockchain can deliver tangible value and stay away from unnecessary investments amounting to "blockchain washing".

The blockchain technology has a tremendous potential to disrupt traditional ways in which we used to do development towards achieving the Sustainable Development Goals by 2030 but there are caveats. When use cases are properly chosen, adequately designed, and implemented, blockchain can deliver its promises beyond the hype mainly by restoring trust and enabling efficiencies. As blockchain is peaking, project managers and development practitioners down the road should anticipate the slow but steady emergence of disruptive new business models, to deliver sustainable development results by moving from log frames to acceleration labs, and from aggregate expertise to disruptive cocreation.

Within the development community, there is a clear need to reboot our expectations in terms of what can be done with and without blockchain technology. The tendency to ride the wave of the blockchain hype under all circumstances without prior due diligence is not the right path forward and can be even detrimental to the very concept of aid effectiveness. The critical starting point for development practitioners would be to build 
rational use cases for blockchain to solve specific development challenges taking into consideration the variety of contexts in which such solutions are needed.

By weighing the tangible benefits expected from a blockchain-backed solution against the extra cost attributed to the additional complexity inherent to the blockchain technology, development workers can seek meaningful tradeoffs and create promising use cases to unlock the truly transformational potential of blockchain as an SDG accelerator that can truly disrupt the way we do development.

As we are heading towards the uncharted territories of the new normal in the aftermath of COVID-19, whatever this will entail for the global order in an increasingly multipolar world, trust is in rare supply more than ever before. The alternative to a system prone to failure could be to replace_blind trust by a trustless ecosystem where transactions are fast, secure, verifiable through an audit trail, and cost-efficient. 


\section{References}

Accenture. (2015). Blockchain Technology: Preparing for Change. Retrieved 5 11, 2020, from https://www.accenture.com/t20160608t052656z_w__/us-en/_acnmedia/pdf5/accenture-2016-top-10-challenges-04-blockchain-technology.pdf

ADB. (2019). Asia-Pacific Trade Facilitation Report 2019 Bridging trade finance gaps through technology. Retrieved 5 25, 2020, from https://www.adb.org/sites/default/files/publication/523896/asia-pacific-tradefacilitation-report-2019.pdf

Al Hilal Bank. (2018). Al Hilal Bank executes the world's first Blockchain Sukuk transaction. Retrieved 5 30, 2020, from https://www.alhilalbank.ae/en/news/2018/november/alhilal-bank-executes-the-worlds-first-blockchain-sukuk-transaction.aspx

Anwar, H. (2020). Public Vs Private Blockchain: How Do They Differ? Retrieved 5 20, 2020, from 101blockchains: https://101blockchains.com/public-vs-private-blockchain/

Aon. (2018). Blockchain technology brings crop insurance to paddy field farmers. Retrieved 58 , 2020, from https://aon.mediaroom.com/news-releases?item $=137772$

Avendano, A., Pico, A., \& Igunma, N. (2019). How Blockchain Can Bridge the Wealth Gap. DEVELOPMENT ASIA. Retrieved 5 8, 2020, from https://development.asia/insight/howblockchain-can-bridge-wealth-gap

Aysan AF, Demir E, Gozgor G Lau CKM. (2019). Effects of the Geopolitical Risks on Bitcoin Returns and Volatility. Research in International Business and Finance 47, 511-518.

Aysan, A. F. \& Bergigui, F. (2020). Blockchain Paths in Rebooting the Global Response to the Sustainable Development Goals after COVID-19. Preprints, 1-29, [online] Available at: doi:10.20944/preprints202010.0074.v1. [Accessed at: 19 August 2021].

Aysan, A. F., Bergigui, F. \& Disli, M., (2021a). Using Blockchain-Enabled Solutions as SDG Accelerators in the International Development Space, Multidisciplinary Digital Publishing Institute (13), 7, pp. 1-24. HYPERLINK "https://doi.org/10.3390/su13074025" https://doi.org/10.3390/su13074025.

Aysan, A. F., Bergigui, F., \& Disli, M. (2021b). Blockchain -Based Solutions in Achieving SDGs after COVID-19. Journal of Open Innovation: Technology, Market and Complexity, 7 (2), 1-16. https://doi.org/10.3390/joitmc7020151.

Aysan, A. F., Demirtaş, H. B. \& Saraç, M., (2021). The Ascent of Bitcoin: Bibliometric Analysis of Bitcoin Research, Preprints, (14), 9, pp. 1-28, [online] Available at: doi 10.20944/preprints202108.0555.v1, [Accessed at: 31 August 2021]. 
Banafa, A. (2020). 8 Key Tech Trends in a Post-COVID-19 World. Retrieved from BBVA: https://www.bbvaopenmind.com/en/technology/digital-world/8-key-tech-trends-in-apost-covid-19-world/

Bengtsson, M., Alfredsson, E., Cohen, M., Lorek, S., \& Schroeder, P. (2018). Transforming systems of consumption and production for achieving. Sustainability Science. Retrieved 5 9, 2020, from https://link.springer.com/content/pdf/10.1007/s11625-018-0582-1.pdf

Berggruen, N. (2018). Here's how blockchain can reduce inequality. The Washington Post. Retrieved 5 8, 2020, from washingtonpost

BitDegree. (2020). What Is a Smart Contract and How Does it Work? Retrieved 2020523, from BitDegree: https://www.bitdegree.org/tutorials/what-is-a-smart-contract/

Blasingame, J. (2019). Blockchain Isn't The End Of Trust, It's The Future Of Trust. Retrieved from Forbes: https://www.forbes.com/sites/jimblasingame/2019/07/18/blockchain-isnt-theend-of-trust-its-the-future-of-trust/\#58ff4ba11596

Blossom. (2018). Muslims Can Now Pay Zakat in Cryptocurrency . Retrieved 5 30, 2020, from Blossom Finance: https://blossomfinance.com/press/muslims-can-now-pay-zakat-incryptocurrency

Blossom. (2019). World's First Primary Sukuk Issuance on Blockchain Closes. Retrieved 5 8, 2020, from https://blossomfinance.com/press/world-s-first-primary-sukuk-issuance-onblockchain-closes

Blossom. (2020). Retrieved 9 13, 2020, from https://blossomfinance.com/

Blossom. (2020). Have cryptocurrency? Pay zakat via Blockchain. Retrieved 9 14, 2020, from https://blossomfinance.com/zakat-via-blockchain

Braden, S. (2019). Blockchain Potentials and Limitations for Selected Climate Policy Instruments. Retrieved 5 9, 2020, from https://www.climateledger.org/resources/BlockchainPotentials-Climate-Policy_2019.pdf

Brand, N. (2018). The Master List of Blockchain Projects in International Development. Retrieved 5 23, 2020, from ICTworks: https://www.ictworks.org/master-list-blockchain-projectsinternational-development/\#.XshYcGgzbIW

Burgess, B., \& Turner, J. (2019). Estimating Financing to the Sustainable Development Goals: Methodology Note for V2.0. Retrieved 5 24, 2020, from https://www.aiddata.org/publications/estimating-financing-to-the-sustainabledevelopment-goals-version-2-0

Capgemini. (2018). Does blockchain hold the key to a new age of supply chain transparency and trust? Retrieved 5 12, 2020, from https://www.capgemini.com/wpcontent/uploads/2018/10/Digital-Blockchain-in-Supply-Chain-Report.pdf 
CarbonX. (2018). Blockchain for good. Retrieved 5 9, 2020, from https://www.carbonx.ca/

Chase, C. (2018). Fishcoin incentivizing blockchain-based traceability in developing nations. Retrieved 5 10, 2020, from https://www.seafoodsource.com/news/environmentsustainability/fishcoin-incentivizing-blockchain-based-traceability-in-developingnations

Cho, J.-H., Chan, K., \& Adalı, S. (2015). A Survey on Trust Modeling. ACM Computing Surveys. Retrieved from http://fs.unm.edu/DSmT/ASurveyOnTrustModeling.pdf

Civic Ledger. (2020). Civic Ledger. Retrieved 5 31, 2020, from https://www.accc.gov.au/system/files/Water\%20inquiry\%20-\%20Submission\%20\%20Civic\%20Ledger\%20-\%2027\%20January\%202020.pdf

CLI. (2019). Navigating Blockchain and Climate Action 2019 State and Trends. Retrieved 5 9, 2020, from https://www.goldstandard.org/sites/default/files/documents/cli_report2019_state_and_trends.pdf

ClimateTrade. (2020). The blockchain platform for carbon offsetting, green financing and sustainable investments. Retrieved 5 9, 2020, from https://climatetrade.com/

CoinTelegrap. (2016). What Are Smart Contracts? Guide For Beginners. Retrieved 5 23, 2020, from https://cointelegraph.com/ethereum-for-beginners/what-are-smart-contractsguide-for-beginners

Cook, B. (2018). Blockchain: transforming the seafood supply chain. WWF. Retrieved 5 10, 2020, from http://awsassets.wwfnz.panda.org/downloads/draft_blockchain_report_1_4_1.pdf

Danho, S., \& Habte, Y. (2019). Blockchain for Financial Inclusion and Mobile Financial Services A study in sub-Saharan Africa. KTH Royal Institute of Technology School of Industrial Engineering and Management. Retrieved from https://www.divaportal.org/smash/get/diva2:1372187/FULLTEXT01.pdf

Deloitte. (2017). Evolution of blockchain technology. Retrieved 5 10, 2020, from https://www2.deloitte.com/tr/en/pages/financial-services/articles/evolution-ofblockchain-technology.html

Deloitte. (2018). Blockchain: A true disruptor for the energy industry, Use cases and strategic questions. $\quad$ Retrieved 27, 2020, from https://www2.deloitte.com/content/dam/Deloitte/us/Documents/energyresources/us-blockchain-disruptor-for-energy-industry.pdf

Deloitte. (2019). Blockchain explained... in under 100 words. Retrieved 5 20, 2020, from https://www2.deloitte.com/ch/en/pages/strategy-operations/articles/blockchainexplained.html 
DinarStandard. (2019). State of the Global Islamic Economy Report, Driving the Islamic economy revolution 4.0. Retrieved 9 13, 2020, from http://www.siicex.gob.pe/siicex/documentosportal/alertas/documento/doc/66196714 4 radC8C6E.pdf

Earth Bank of Codes. (2018). Earth Bank of Codes. Retrieved 5 10, 2020, from https://earthbankofcodes.worldsecuresystems.com/

Encrypgen. (2018). Gene-Chain. Retrieved 5 23, 2020, from https://encrypgen.com/

FollowMyVote. (2012). Introducing a secure and transparent online voting solution for the modern age. Retrieved 5 23, 2020, from https://followmyvote.com/

Fraga-Lamas, P., \& M. Fernández-Cara, T. (2020). Leveraging Blockchain for Sustainability and Open Innovation: A Cyber-Resilient Approach toward EU Green Deal and UN Sustainable Development Goals. IntechOpen. doi:DOI: http://dx.doi.org/10.5772/intechopen.92371

Ghosh, J. (2019). 3 obstacles that stand in the way of the UN's Sustainable Development Goals. Retrieved 5 24, 2020, from WEF: https://www.weforum.org/agenda/2019/09/3obstacles-that-stand-in-the-way-of-the-un-s-sustainable-development-goals/

Goldstein, D., \& Tillemann, T. (2020). Blockchain Impact Ledger. Retrieved 5 22, 2020, from New America: https://www.newamerica.org/digital-impact-governanceinititiative/blockchain-trust-accelerator/reports/blockchain-impact-ledger/

Gopalakrishnan, P., \& Radhakrishnan, R. (2019). Blockchain Based Waste Management. International Journal of Engineering and Advanced Technology (IJEAT), 8(5). Retrieved 5 8, 2020, from https://www.researchgate.net/publication/334162200_Blockchain_based_Waste_Man agement

Grüner, A., Mühle, A., Gayvoro, T., \& Meinel, C. (2018). A Quantifiable Trust Model for Blockchain-Based Identity Management. IEEE. Retrieved from https://ieeexplore.ieee.org/document/8726703

Hutt, R. (2016). All you need to know about blockchain, explained simply. Retrieved 5 20, 2020, from World Economic Forum: https://www.weforum.org/agenda/2016/06/blockchainexplained-simply/

IBM. (2018). Energy Blockchain Labs Inc. Retrieved 5 9, 2020, from https://www.ibm.com/casestudies/energy-blockchain-labs-inc

IBM. (2020). Farmer Connect Uses IBM Blockchain to Bridge the Gap Between Consumers and Smallholder Coffee Farmers. Retrieved 5 8, 2020, from https://newsroom.ibm.com/2020-01-06-Farmer-Connect-Uses-IBM-Blockchain-toBridge-the-Gap-Between-Consumers-and-Smallholder-Coffee-Farmers 
ICD. (2019). Islamic Finance Development Report 2019. Islamic Corporation for the Development of the Private Sector (ICD) . Retrieved January 10, 2020, from https://icdps.org/uploads/files/IFDI\%202019\%20DEF\%20digital1574605094_7214.pdf

Invest In Estonia. (2018). Digital revolution in Estonia's energy sector: WePower is the first Blockchain firm to tokenize an entire grid. Retrieved 5 31, 2020, from https://investinestonia.com/wepower-is-the-first-blockchain-firm-to-tokenize-anentire-grid/

IRENA. (2019). Blockchain Innovation Landscape Brief. Retrieved April 16, 2020, from https://www.irena.org/-

/media/Files/IRENA/Agency/Publication/2019/Feb/IRENA_Landscape_Blockchain_2019 .pdf?la=en\&hash=1BBD2B93837B2B7BF0BAF7A14213B110D457B392

Jayachandran, P. (2017). The difference between public and private blockchain. Retrieved 520 , 2020, from IBM: https://www.ibm.com/blogs/blockchain/2017/05/the-differencebetween-public-and-private-blockchain/

Joost, H., \& Andrej, Z. (2018). Blockchain for Sustainable Development Goals. Retrieved 5 23, 2020, from https://www.rug.nl/research/portal/files/63204374/351162_Paper_Blockchain_4SDGs _A4_RUG_CF_LRdef_2_.pdf

Kewell, B., Adams, R., \& Parry, G. (2017). Blockchain for good? Strategic Change. doi:https://doi.org/10.1002/jsc.2143

KryptoPal. (2018). Putting the power of blockchain into mainstream consumer hands. Retrieved 5 30, 2020, from https://kryptopal.io/company/

Lafortune, G. (2020). Europe Sustainable Development Report. Sustainable Development Solutions Network. Retrieved 5 24, 2020, from https://irpcdn.multiscreensite.com/6f2c9f57/files/uploaded/ESDR\%20Highlights.pdf

Leber, J. (2018). Betting on Blockchain to Put Truly Sustainable Seafood on Dinner Plates. Retrieved $510,2020, \quad$ from https://www.newsdeeply.com/oceans/articles/2018/02/28/betting-on-blockchain-toput-truly-sustainable-seafood-on-dinner-plates

Lizcano, D., Lara, J. A., White, B., \& Aljawarneh, S. (2020). Blockchain-based approach to create a model of trust in open and ubiquitous higher education. Journal of Computing in Higher Education. Retrieved from https://link.springer.com/article/10.1007/s12528-01909209-y\#citeas

Malhotra, M. (2020). A comprehensive list of blockchain platforms to look for in 2020. Retrieved 5 23, 2020, from ValueCoders: https://www.valuecoders.com/blog/technology-andapps/a-comprehensive-list-of-blockchain-platforms-to-look-for-in-2019/ 
Massessi, D. (2018). Public Vs Private Blockchain In A Nutshell. Retrieved 5 20, 2020, from Medium: https://medium.com/coinmonks/public-vs-private-blockchain-in-a-nutshellc9fe284fa39f

Mirchandani, A. (2018). POCertify - Halal Certification on Blockchain. Retrieved 5 30, 2020, from Medium: https://medium.com/@amudotcom/pocertify-halal-certification-onblockchain-71a2da16f8b8

Mougayar, W. (2016). If You Understand Google Docs, You Can Understand Blockchain. Retrieved 5 20, 2020, from Coindesk: https://www.coindesk.com/understand-google-docs-canunderstand-blockchain

Murray, M. (2018). Blockchain explained. Retrieved 5 20, 2020, from Reuters Graphics: http://graphics.reuters.com/TECHNOLOGY-BLOCKCHAIN/010070P11GN/index.html

Murtaza, S. (2019). Blockchain based GainForest offers incentives for Amazon caretakers. Retrieved 5 10, 2020, from https://www.cryptopolitan.com/blockchain-basedgainforest-offers-incentives-for-amazon-caretakers/

Nikolakis, W., John, L., \& Harish, K. (2018). How Blockchain Can Shape Sustainable Global Value Chains: An Evidence, Verifiability, and Enforceability (EVE) Framework. Sustainability. doi:10.3390/su10113926

OConnell, J. (2019). Is Blockchain Halal? These Startups Are Transforming Islamic Finance. Retrieved 5 30, 2020, from https://saraycon.com/is-blockchain-halal-these-startups-aretransforming-islamic-finance/

OECD. (2019). Rethinking Innovation for a Sustainable Ocean Economy. Retrieved 5 10, 2020, from http://www.fao.org/fi/staticmedia/MeetingDocuments/BlueHope/secondmeeting/Blue\%20Economy\%20blue\%20g rowth/Rethinking\%20Innovation\%20for\%20a\%20Sustainable\%200cean\%20Economy.p df

PositiveBlockchain. (2020). Positive Blockchain Database. Retrieved 5 23, 2020, from https://positiveblockchain.io/tableview/

Power Ledger. (2020). RENeW Nexus, Australian Government, Australia. Retrieved 5 31, 2020, from Power Ledger: https://www.powerledger.io/projects/renew-nexus/

PwC. (2017). Use Cases for. Blockchain. Technology in Energy \&. Commodity Trading. Retrieved 5 11, 2020, from https://www.pwc.com/gx/en/industries/assets/blockchaintechnology-in-energy.pdf

Rabbani, M., Khan, S., \& Thalassinos, E. (2020). FinTech, Blockchain and Islamic Finance: An Extensive Literature Review. International Journal of Economics and Business Administration. Retrieved 5 30, 2020, from https://www.ijeba.com/journal/444/download 
Ranjan, R., Hung, S., Mohindroo, A., \& Vignesh, K. (2019). Powering the Future of Finance Through Blockchain. Retrieved 5 30, 2020, from https://www.infosysbpm.com/newsroom/analyst/Documents/everest-financeblockchain.pdf

Rosic, A. (2016). What is Blockchain Technology? A Step-by-Step Guide For Beginners. Retrieved 5 20, 2020, from Blockgeeks: https://blockgeeks.com/guides/what-is-blockchaintechnology/

Runde, D., Metzger, C., \& F. Abdullah, H. (2020). Covid-19 Demands Innovative Ideas for Financing the SDGs. Retrieved 5 24, 2020, from Center for Strategic and International Studies: https://www.csis.org/analysis/covid-19-demands-innovative-ideas-financing-sdgs

Ruokonen, M. (2020). Covid-19 and digitalisation: 4 areas of tech set to boom post-pandemic. Retrieved 5 20, 2020, from information Age: https://www.information-age.com/covid19-digitalisation-tech-boom-post-pandemic-123488670/

Ryan, P., \& Horner, J. (2019). Blockchain Standards for Sustainable Development. Journal of ICT. doi:10.13052/jicts2245-800X.733

Saberi, S., Kouhizadeh, M., Sarkis, J., \& Shen, L. (2018). Blockchain technology and its relationships to sustainable supply chain management. 2019: International Journal of Production Research. Retrieved from https://www.tandfonline.com/doi/epub/10.1080/00207543.2018.1533261?needAcces $s=$ true

Sachs, J., Schmidt-Traub, G., Kroll, C., Lafortune, G., \& Fuller, G. (2019). Sustainable Development Report 2019. Bertelsmann Stiftung and Sustainable Development Solutions Network (SDSN).

Retrieved

from https://s3.amazonaws.com/sustainabledevelopment.report/2019/2019_sustainable_d evelopment_report.pdf

Schlapkohl, K. (2019). What's the difference between a blockchain and a database? Retrieved from IBM: https://www.ibm.com/blogs/blockchain/2019/01/whats-the-differencebetween-a-blockchain-and-a-database/

Schroeder, P., Anggraeni, K., \& Weber, U. (2018). The Relevance of Circular Economy Practices to the Sustainable Development Goals. Journal of Industrial Ecology. doi:10.1111/jiec.12732

Scruggs, G. (2018). Blockchain, Al hailed as new tools to protect high seas. Retrieved 5 10, 2020, from https://www.reuters.com/article/us-oceans-un-fishing-feature/blockchain-aihailed-as-new-tools-to-protect-high-seas-idUSKCN1NX1EH

SelfKey. (2020). Understanding Public vs. Private Blockchain. Retrieved 5 20, 2020, from https://selfkey.org/understanding-public-vs-private-blockchain/ 
Shein, E. (2019). How Blockchain Changes the Nature of Trust. Retrieved from The Linux Foundation: https://www.linuxfoundation.org/blog/2019/01/how-blockchain-changesthe-nature-of-trust/

Shermin, V., Tatjana, N., Wildenberg, M., \& Rammel, C. (2019). BLOCKCHAIN, WEB3 \& THE SDGS. Retrieved from https://epub.wu.ac.at/7464/1/SustainableDevelopment\%20Report_BlockchainWeb3_S DGs.pdf

Subhanij, T., \& Hasannudin, Z. (2020). Financing SDGs Under A New Normal: Challenges And Response To COVID-19 Pandemic. Retrieved 5 24, 2020, from ESCAP: https://www.unescap.org/blog/financing-sdgs-covid-19\#

Suen, P. (2020). Waterig. Retrieved 5 31, 2020, from MIT Solve: https://solve.mit.edu/challenges/sustainable-urbancommunities/solutions/162/application\#solution-subnav-offset

Toshendra, S. K. (2020). Top 2020 blockchain platforms for building blockchain-based applications. Retrieved 5 23, 2020, from Blockchain Council: https://www.blockchaincouncil.org/blockchain/top-2020-blockchain-platforms-for-building-blockchain-basedapplications/

UN DESA. (2020). Shared responsibility, global solidarity: responding to the socio-economic impacts of COVID-19. Retrieved 5 24, 2020, from https://unsdg.un.org/sites/default/files/2020-03/SG-Report-Socio-Economic-Impactof-Covid19.pdf

UN DESA. (2020). Sustainable Development Knowledge Platform. Retrieved 5 24, 2020, from https://sustainabledevelopment.un.org/vnrs/

UNCTAD. (2020). Coronavirus update: COVID-19 likely to cost economy \$1 trillion during 2020, says UN trade agency. Retrieved 5 20, 2020, from UN News: https://news.un.org/en/story/2020/03/1059011

UNEP DTU. (2019). Climate change challenges and blockchain opportunities. Retrieved 59 , 2020, from https://unepdtu.org/wp-content/uploads/2019/02/udp-climate-changeblockchain.pdf

UNFCCC. (2017). How Blockchain Technology Could Boost Climate Action. Retrieved 5 9, 2020, from https://unfccc.int/news/how-blockchain-technology-could-boost-climate-action

UNHCR. (2019). Refugee Zakat Fund 2019 Mid-Year Report. Retrieved 9 13, 2020, from https://zakat.unhcr.org/wp-content/uploads/2019/08/UNHCRs-Refugee-Zakat-FundMid-Year-Report-2019-FINAL-v1.pdf 
UNHCR. (2019). Refugees: the most in need of zakat funds. Retrieved 9 13, 2020, from https://zakat.unhcr.org/wp-content/uploads/2019/04/UNHCR-Annual-Zakat-Report2019-En.pdf

United Nations. (2020). Communications materials. Retrieved 5 24, 2020, from https://www.un.org/sustainabledevelopment/news/communications-material/

University of Canterbury. (2019). Blockchain benefits sustainable food production. Retrieved 58 , 2020, from https://phys.org/news/2019-07-blockchain-benefits-sustainable-foodproduction.html

Velosoa, B., Leal, F., Malheiro, B., \& Moreira, F. (2019). Distributed Trust \& Reputation Models using BlockchainTechnologies for Tourism Crowdsourcing Platforms. Procedia Computer Science. Retrieved from https://reader.elsevier.com/reader/sd/pii/S187705091931765X?token=F023D1ED4DD 7FA3A8F8C6818F6F41900E3885329A51BDB2B7404DC3944B7D6C3647084B0574882B4 AB9BAF1D2706AF8B

Vota, W. (2018). Blockchain Use Case Failure: 43 Projects and Zero Impact Found. Retrieved 5 23, 2020, from ICTworks: https://www.ictworks.org/blockchain-impactfailure/\#.XskkC2gzbIX

WaterChain. (2018). World Economic Forum Highlights How Technologies Like WaterChain Could Solve World's Water Problem. Retrieved 5 31, 2020, from Medium: https://medium.com/waterchainio/world-economic-forum-highlights-howtechnologies-like-waterchain-could-solve-worlds-water-problem-b0191440a289

WEF. (2014). Towards the Circular Economy: Accelerating the scale-up across global supply chains. World Economic Forum. Retrieved 8 31, 2020, from http://www3.weforum.org/docs/WEF_ENV_TowardsCircularEconomy_Report_2014.pd $f$

WEF. (2017). Harnessing the Fourth Industrial Revolution for Oceans. Retrieved 5 10, 2020, from http://www3.weforum.org/docs/WEF_Harnessing_4IR_Oceans.pdf

WEF. (2018). Building Block(chain)s for a Better Planet. Retrieved April 4, 2020, from http://www3.weforum.org/docs/WEF_Building-Blockchains.pdf

WEF. (2020). Redesigning Trust: Blockchain Deployment Toolkit. World Economic Forum. World Economic Forum. Retrieved 5 25, 2020, from http://widgets.weforum.org/blockchaintoolkit/contributors

Werbach, K. (2019). The Blockchain and the New Architecture of Trust. Retrieved from American Bar

Association: https://www.americanbar.org/groups/business_law/publications/committee_newslett ers/legal_analytics/2019/201904/blockchain/ 
Whitehead, R. (2019). New halal blockchain traceability tool touted as a supply chain 'gamechanger'. Retrieved 9 13, 2020, from https://www.foodnavigatorasia.com/Article/2019/07/02/New-halal-blockchain-traceability-tool-touted-as-asupply-chain-

gamechanger?utm_source=copyright\&utm_medium=OnSite\&utm_campaign=copyrigh $\mathrm{t}$

Wood, M. (2019). Korea Telecom to launch halal food traceability blockchain. Retrieved 9 14, 2020, from Ledger Insights: https://www.ledgerinsights.com/korea-telecom-halaltraceability-blockchain/

Xiao, Y., \& Fan, Z. (2020). 10 technology trends to watch in the COVID-19 pandemic. Retrieved 5 20, 2020, from World Economic Forum: https://www.weforum.org/agenda/2020/04/10-technology-trends-coronaviruscovid19-pandemic-robotics-telehealth/ 